Tejidos is a community artistic project that aims to develop a community to give voice to the particular stories of those who live in Oaxaca (women and the deaf community) and Mexico City (older adults). The project has been funded by the Arts Council England (2018) and Iberescena (2019). "Theatre of Yes" is a methodology that uses the power of beauty as a language to break the stereotypes of situations that society views with apathy. By creating a provocative and emotional performance, we can transform the lives of people who suffer social exclusion.

Yet, how can we create a high-quality performance with people who are not professional actors but have stories that should be shared? How can we use powerful performances as an axis of change? How can emotions be the motor for the struggle against the social oppression that many groups suffer?

Artistic work has helped us to observe how creativity pushes people to find a freer self and, above all, to be close to the essence of the human being. The base of the Theatre of YES brings together the universal characteristics, honesty, simplicity, humility and generosity. The characteristics of the methodology developed with these groups are the yes as a weapon against the non-worthy self, beauty as the axis of change, physical theatre according to the Lecoq methodology.

Keywords: Theatre of Yes, beauty, Greek Choir, social transformation, quality as excellence

Marina Pallarès Elias is the artistic director of Acting Now based in the UK and Rebozo Teatro based in Mexico. Her passion is to create high-quality performances using the personal stories of people who do not have the opportunity to be heard. She has worked in Mexico with women, deaf people and the elderly; in the UK with people with mental health challenges, learning disabilities, LGBTQ+, refugees, women; in Italy with people with physical disabilities; in Spain with the LGBTQ+ Zinegoak Film Festival; in Germany with migrants. She has received the prestigious Iberescena Award and the Award of the Arts Council England. She has presented her work at the National Theatre Conference in Mexico (2019), at the Cambridge University Conference and in Madrid (2018).

marina@actingnow.co.uk 


\section{The Theatre of Yes: Beauty as the Axis of Change for the Transformation of Communities Through Their Own Stories}

Marina Pallarès Elias

Acting Now, UK, and Rebozo Teatro, Mexico

The basics of the Theatre of Yes have been developed in recent years to show the world the theatrical language that I use in multiple international projects. It is a methodology developed from action in the creative framework of working with people in multiple communities. The Theatre of Yes uses personal stories from communities at risk creating performances of emotional quality. Instead of creating a pamphlet piece designed to intellectually inform the audience about oppressive circumstances, I propose an emotional piece that showcases often hidden, untold or overlooked personal stories. The performance of such stories is intended to spark collective catharsis in both the performers and the spectators.

The Theatre of Yes is based on some universal characteristics that human beings possess, namely honesty, beauty, simplicity, humility and generosity. These qualities surround us everywhere, although sometimes they are difficult to find. Trauma, injustice and distress disconnect us from our own life and our future, but, at the same time, they are part of them. I work with people who often do not feel beautiful, feel a lot of guilt and have endured a lot of suffering. The Theatre of Yes facilitates the creation of spaces in which to connect with the world and humanise ourselves. These are spaces in which to accept our own narrative, open it up to the world from within a safe and creative space, spaces in which the tool of physical theatre supports us and facilitates a new dimensionality in our life journey. It also allows us to see our life in a much more flexible way and to understand that we are not victims or guilty of the specific circumstances in which we find ourselves. In this way, it predisposes us to be able to develop a fresh look at other narratives about ourselves. The Theatre of Yes, therefore, opens, expands, cleans, yields, reclaims and reconnects.

In 2018, the Arts Council England offered me a scholarship to work in Oaxaca for seven weeks. In 2019, Ibersecena granted me another one to work with older adults in Mexico City. The scholarship was an investigation of using this language in a context like Mexico, working with fourteen women participants and twenty-five members of 
the deaf community. The women were aged between 20 to 55, residents of the city or its surroundings. It took four intensive days to learn the language of the Theatre of Yes and four consecutive weeks for the creation of the work. The deaf group consisted of young people aged 15 to 25 and volunteers who translated. Most were in high school, and a few had jobs. The work was done in six hours a week over seven weeks.

My story began in 1997. I was fifteen and was experiencing a difficult time as a teenager. My family was broken, and I was angry, disappointed and desperate to escape from any pain. One day, one of my teachers at secondary school invited me to join the theatre group. At first, I resisted, but then I decided to attend. This group saved my life. I felt included and loved. For the first time, people were admiring me! From that moment, I understood what my purpose was in life: to use theatre to help others to transform their lives in the way that theatre had done so for me. Over time, I began to work using theatre as a tool for social transformation, drawing on Theatre of the Oppressed and other techniques. I was lucky to have the opportunity to travel and to develop projects with multiple communities. However, I began to consider a troubling question. When I went to see a community performance, in which the actors could be people with disabilities or with mental health issues, often the performance standard lacked quality. Although the performance was developed with the best intentions, the beauty of theatre was not there. My thoughts as an audience member were that "they did their best" and "they could not do any better". However, in thinking these thoughts, I reproduced the same paternalistic concepts against which I was trying to fight. I started wondering how I could use my theatre expertise to develop a language of theatre that would enable the creation of a high-quality performance using the personal stories of people who need to be heard. Other questions came to mind: How to create quality plays by working with people who are not professional actors but have brutal honesty? Why is creating quality work essential when working with communities? Where are the professional ethics when working with this vulnerable material? How does theatre, without the concept of applied theatre, only theatre, facilitate the transformation of people? How can theatre profoundly affect the people who come to see these works? What theatrical language do we have to use to put forth the scenic quality that the stories deserve?

With my training in Lecoq pedagogy and my combination of experiences, I have been able to develop a form of theatrical language that combines beauty with the exploration of trauma, the honesty of the actor with the humility of working with a group, emotion as the axis of the trip theatrical, the body-emotion-voice path and the choir as the essence of the transmission of these acquired emotions. It is a theatrical language that allows us to reach emotional honesty, the beauty of the dark, but always in a safe context. 
Furthermore, I use the Theatre of the Oppressed, a theatrical form oriented towards liberation from oppressive beliefs and situations. TO, as it is sometimes abbreviated, addresses social, political and economic issues such as racism, poverty, homelessness, violence against women, religious and ethnic conflicts and environmental threats (see Gökhan). I also use psychodrama, which can be considered not only as a method of psychotherapy but also a laboratory, in which psychosocial problems are explored through dramatic tools and participants' own behaviours. A protagonist is the main actor in the work. A therapist, acting as director, guides the play; the others play the roles the protagonist wants to develop, and the audience watches the play (see Moreno and Sullivan et al.).

Therefore, on the one hand, it focuses on the reflection process to see alternatives for community and personal context and psychodrama works in a therapy context. On the other hand, the Theatre of Yes focuses on the cathartic experience for the audience and actors together, creating an emotional, high-quality theatre performance that breaks the stereotypes and prejudices that community groups have to face in daily life.

In my theatrical research, I needed to find a theatrical language that could be adapted to human beings without distinguishing race, culture, diversity or gender. As long as they had stories to tell, the methodology could be used. The Theatre of Yes brings together the universal characteristics that human beings have; honesty, beauty, simplicity, humility and generosity. The theatre of Yes provides spaces to connect with the world, to humanise us to say enough, say NO. We work with people who often do not feel beautiful, with much guilt, much suffering.

In this paper, I describe my experiences working in Mexico. In 2020, 3,723 women were killed in Mexico. Women suffer all kinds of violence from health, justice and education institutions or in personal relationships. This methodology invited these women to create a space to accept their own narrative, to open it up from within a safe space and to use the tool of physical theatre to facilitate a new dimensionality of their life journey. They had the opportunity to share stories about the violence that they face in their lives. In doing so, it helped them to realise that it is a common pattern related to gender identity and helped them to explore alternative ways of thinking to the established narrative.

The Theatre of Yes is the collective process of the transformation of the individual and group. It is the creative journey that the participants take, connecting with emotions, with their own traumas, with their own stories.

With the Theatre of Yes, over the years, I have realised the importance of being seen before the public. It is there where the rules of the game begin to change, people without a visualisation within society, marked in their social domains, feeling guilty 
of so many stories, where now, they go on stage, to tell, to express, and those who typically decide the laws from this society, we sit and listen. These works have the characteristic of being provocative, of great emotion and of extreme quality. Likewise, without giving less importance, the public sample of these works offers a cathartic relationship between the public and actors where the bankruptcy of prejudices about the actors, which in other circumstances can be seen as hopeless and vulnerable people.

The word catharsis as defined in the Merriam-Webster Encyclopaedia of Literature derives from the Greek word for "cleansing" or "purification". As Rionaldo expresses it, there are "two essential components of catharsis: the emotional aspect (strong emotional expression and processing) and the cognitive aspect (insight, new realisation, and the unconscious becoming consciousness)" (2). Catharsis thus results in a positive change.

\section{Characteristics of the Theatre of Yes}

The Yes as a political-ethical position in a world where the "You are not enough" does not prevail in the cultural discourse. Often, the participants who attend have the characteristic that this position is not impregnated in all its spheres. We will use the Yes as a political act to be free to say NO. To create spaces of freedom where acceptance is the main thing, the Yes as a means of independence; the Yes to discover new paths never undertaken; the Yes to accept other bodies, other emotions, and the Yes to say NO to oppression, discrimination.

Beauty is the axis of change. Beauty is one of the most important axes of this theatre. Beauty in the language of this theatre is understood as a weapon to fully open unhealed wounds, to find justice in such pain, to name submerged emotions. It helps us to break patriarchal patterns, to see alternately that you are going away from a boring morality. There is no dialogue with the public without that effective honesty. We need dialogue to change prejudice. Rather than an intellectual dialogue to understand a concept, this will be an emotional dialogue where, through sharing emotional stories, we can understand the humanity in suffering and the lessons people have learned in their journeys.

Without that acceptance of oneself, without being present in soul, body and heart. We propose a theatre without artifice, without masks, a theatre of empowerment and self-acceptance. It is a theatre of the acceptance of difference, and above all, the empowerment of those who are excluded because they have not been able to adapt in a society that only values the economic winner. It helps us break patriarchal patterns, 
see possible alternatives far from boring morality. Nothing can destroy beauty; it always depends on how we see it and the overture we have towards it. Beauty is our weapon of combat in the dark, shit, hate.

Without beauty, there is no work, and there is no possible narrative. Beauty supports our stories of horror and hope; it helps us digest what has never been said to expose what has sometimes been secretly lived. We see as beautiful what others see as disgusting. Trauma as a beautiful element - here, I use beauty as a political means to define the world we want. It is the process of recognising others, of seeing others as an opportunity. Beauty helps us understand the world more, the processes where they lead people to commit acts difficult to find an answer such as suicide attempts, psychotic attacks, abandonment. Meli told her story one day. She had not been able to meet her grandparents because her father always prevented her. She insisted on seeing them, on knowing them. The grandparents lived in another country, and she could not go to see them alone. The young woman dreamt of meeting them. Yet, out of fear that she would discover his own turbulent past, her father did not want her to know them and always made up excuses. One day, an acquaintance told her that her grandparents had died without her knowing them. She felt devastated, furious with her father. How to face a story of this kind, showing all these terrible feelings? When creating the story, every emotion she shared gave her a movement. The group was fundamental in that emotional movement. The group endured Meli, making equal movements, or the opposite. For example, in a movement of pain, she went to the floor, covering her body. The rest of the group covers her body, saying: "Meli, you are not alone. Meli, you are not alone. Meli, you are not alone." The piece helped her to express her history, unlocking our judgements of distant stories. Afterwards, Meli shared with the group how this process allowed her to reconcile with herself and put an end to the guilt that she had been holding onto for years. In other words, she was able to see herself with more love and less hate. Beauty enables us to have the time to understand the causes of events and their consequences. Beauty connects us with genuine emotions. It helps us to digest the horror, the trauma, to accept, to move forward. Not to accept to build another future, but rather to adapt, to feel more secure. Beauty helps us to see it in another way, to see the inside of that trauma, to explore emotions, to find the reason for so many questions, to eliminate established stigmas.

A theatrical result gets through only with excellence. We can only break prejudices and stereotypes if we reach the emotions of the spectators. Emotions prevent the audience from over-analysing the performance and judging the story on a rational level. Emotions maintain a connection between the audience and actors, bringing them closer and allowing them to experience the same journey. Emotions 
help to develop an understanding of the causes, reasons and consequences around a character's actions. Therefore, the audience can empathise with these communities rather than being judgmental. That is why we, the theatre experts, must know how to do quality work without hesitation. These works have the characteristics of showing great emotion and of extreme quality. This aspect brings us from the micro situations to the macro situations that often overwhelm us, making us feel powerless to respond. It is about understanding, from many points of view, how emotions take on the role of guides. Therefore, the actors, from their stories, become catalysts for collective empowerment by approaching and connecting. We are no longer alone, isolated in our own faults, but rather a unified group.

Because of my conviction that the quality of a play is a requirement in the Theatre of Yes, it hurts when I see plays developed by a group, made with the best intention, but for which quality is not an important point. As a result, the goal we want to achieve, using theatre to break stereotypes, can be counterproductive. Hence the need for the Theatre of Yes, the search for that quality, the beauty of their bodies, their own stories, so that these people show themselves as they are. It is time to go further, to accept ourselves, to love each other, to see how wonderful we are. It's time to start transforming into who we are: darkness and beauty, despair and union, passivity versus action.

Physical theatre uses the Lecoq methodology. Using the magic of physical theatre, I intend to use theatre as the inspiration for breaking with the constraints of the realist dimension. Therefore, we create entirely new worlds in which we can express our emotions and stories "simply", using the effort of our bodies in movement and in voice. Physical theatre reconnects us with our bodies and emotions in an exciting and challenging way, open to anyone with a curious body and mind.

\section{In personal stories, the Theatre of Yes does not seek to find the solutions} for change but to tell stories. In those stories, you can find dreams of change or find that history develops those changes that happened to the person. In this methodology, the change is in the honesty, generosity and humility of the stories and the collective catharsis generated between actors and spectators. When you see us, look at us and connect. This connection will be the rebellion: a committed theatre, seeing alternatives and empowering protagonists to refuse to reproduce the norms established by a culture that benefits itself, leaving those of no interest aside. These alternatives are created from understanding our own narratives and unleashing the space of victimisation or guilt that many people have in their lives. 


\section{The political and ethical basis}

The Theatre of Yes is a political act. I mean, it is an act in which we as theatre creators have to be aware of our position of respecting the people for whom we work. As creators, we do not have to ignore our privileges (for example, me, woman, white, European, heterosexual), but to be aware of them when working with people at risk of social exclusion like the homeless, people with learning disabilities, refugees, people with mental health challenges, young women and members of the LGBTQ+ community. Through that awareness, we can enter into more authentic dialogue with the people with whom we work. If we ignore who we are but detect when our speech can prevail over the stories of the people with whom we work, we will repeat the already established patterns. But we understand that our role is that of creators and that objectivity is impossible and unfeasible. Therefore, our ideas and thoughts come from a subjectivity that we welcome as long as we are aware of it and work to give it the space it deserves. As directors, we have to assume responsibility but remain very aware of the power we have. Power is synonymous with responsibility. If we want that magical opening by our participants, we need to understand very well our role, which is to develop a play with their own stories using theatrical language at their service, where creativity serves to expand and bring these closer to the spectators. For example, in Mexico, a deaf man shared his experience of being mistreated by his family because of his hearing impairment. He felt safe sharing his story, but it occurred to me that he might not be ready to take action and create something from it. This observation was my subjective one from my position of power, and I was concerned about causing him pain. However, I was aware of this thought and embraced it, realising that he was both responsible for and capable of changing his own situation through the process of the Theatre of Yes.

The terrific comments include: "They did the best they could"; "As they are disabled, limited, with problems to express themselves". But, to understand what "we, white, first world, know", nothing happens if the quality is not at the right level. This lack of quality is the victim of our lack of responsibility as professionals. Assistance perpetuates the victim in continuing to be a victim; in that help is offered as a value to perpetuate that limitless power. The commitment lies in social responsibility; if we intend to support people for a vital transformation, the quality of work must go hand in hand as a professional responsibility.

Breaking prejudices. The creation of the work is to break the morality imposed by the dominant culture from the morality (what to do and how to behave) by welcoming the contradictions that the stories may have by breaking the social order. In this state of competition, of power relations, the Theatre of Yes process has to be an absolute collective process. If the state of power continues, there is a risk of falling into an 
absolute ego "self-criticise, self-control, self-perfect". Breaking prejudices will thus be the rebellion, a committed theatre, from the community, honesty, humility and generosity in seeing alternatives and empowering the protagonists to be themselves.

\section{The Greek chorus as a collective force}

The choir is one of the main engines of my work. This choir comes from the inspiration of the Greek chorus.

In the context of Greek ancient theatre, the chorus, a term taken from ancient

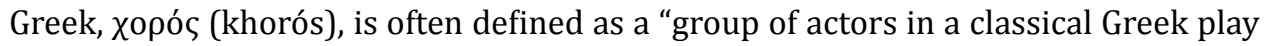
(therefore either tragedy or comedy) typically serving to formulate, express, and comment on the moral issue that is raised by the dramatic action or to express an emotion appropriate to each stage of the dramatic conflict" ("Greek Chorus").

The chorus of the Theatre of Yes connects with the role of the ancient Greek chorus in exploring the emotions of the characters. That theatrical form, so beautiful and inclusive, allowed a trip on many axes from the depths of the bowels, through repressed emotions, going up to the actions taken and the words spoken. The choir goes straight to the repressed emotion, bluntly, without possible excuses. It makes possible a new communication between the participants, in the group's trip, where that story is ours, of the actors and the spectators.

Reasons that give absolute power to this methodology are:

- The possibility to express with the action and voice the deepest emotions that the characters are feeling. It reveals the wishes that many times can be contradictory with those that the character manifests at that time. Therefore, answering so many questions never mentioned and hidden in the well of our souls. We imagine that a character wants to leave a space that feels very oppressed, while his oppressor, his partner, tells him that he is well where he is, inside, he dreams of not returning, dreams of going back and not marrying that person. The choir represents all those dreams. It makes possible the sample that, although it looks like a dead person in life, inside, he still shows his hidden dreams.

- Amplify the emotions of the characters. It is not the same to say "go" from one character to another, that there is a chorus behind the characters supporting and interpreting the deep intention. For example, one brother has realised the betrayal of the other. He told him a secret, and he has told everyone. The brother is disappointed with the other and says, "Go". If you say it, it will only be realistic and possibly flat. Imagine instead that this character has a chorus behind him that 
also repeats "Go away" three times, making a movement in unison with the hands of rejection. The result is that amplifying this "go" helps the viewer to connect more deeply with this intention.

- Supports characters full of pain. Working with personal stories is very sensitive and delicate work. Often, the participants want to talk about personal stories, but the process of doing so is very painful. Yeli, a woman from the Oaxaca project, wanted to talk about how her family pushed her to study law because her mother, her uncle and her brother had done so. She really wanted to study theatre, but she ended up working as a lawyer and the sexist abuse she received from her boss without being able to change that. In the end, she explained how she revealed all of that. I proposed a chorus that would mean the other Yelis, their other selves. Those took care of her in the process, that she opened her eyes with a lot of love, with a lot of delicacy that they suffered with her. Therefore, in the process of reviving and putting Yeli's story into life, she would not feel helpless. All the Yelis, all the women, all of us were Yeli. That intense pain is no longer of a single person but is shared with the collective.

- Unravel. No one is disposable. We are all useful and necessary. In my view, within classical theatre, the one who does it best stands out, and those who do not have so much talent are relegated. On the contrary, in the Theatre of Yes, there is no such concept of talent connected with the ego. It is not valued who knows more or less. In this methodology, the drive is the quality of the work, which is independent of the qualities that the dominant culture imposes on us. All people can reach it.

\section{Everything is possible, everything has meaning}

Any idea can develop a story. In this methodology, the idea is not the most important, much less; we are not looking for the most incredible story. It may sound weird. We are used to looking for the best idea, unique or adapted from others. And from that idea, we start. If we don't have that idea, we don't even know how to start. Here comes the first discrimination with the people with whom I work. As they have no space to find those ideas, they feel like passive beings feeling that their only function is to follow those who do have those bright ideas where power is manifested. "How will I have an idea if I'm not enough? How will I emphasise if I'm nothing?" Also, to highlight that if we look for the most incredible story, we do it from a mental point of view, from a narrative logic, we go to the final result, which restrains us and takes away the freedom. 
I advocate for a simple story, for simple movements. Simple movements allow the audience to connect with the internal emotion that the story is expressing. Complex movements can mean that the emotion is lost, resulting in the spectators disconnecting from the essence of the story and returning to their position of judgment. Simpler and cleaner, the result will be more powerful and therefore more beautiful. I constantly repeat that I am not interested in somersaults in the air. They only interest me if they have an emotional justification. We must break the naturalistic language that represses us for the rest of our lives to find a more equitable and balanced language. Inside the questions, there are hidden emotions and true answers. Simplicity is a weapon that separates us from imperial logic in a living space that seems to be more complex.

\section{Theatrical inspiration is out: the world and its nuances as theatrical inspiration}

The theatre that I propose is a theatre of deep emotions, of hidden stories of blocked situations. In creation, we have two ways of creating; one from human nature another from the character's psychology. What is the difference? The first, as Lecoq (101) says, inspiration is outside, others, natural elements such as water, air, earth or fire, how they move or how they become other elements, inspire us. Objects, their forms and their falls inspire us. The geometry of circles, triangles. The shapes of the mountains. The movements of animals and their relationships. If instead, we limit ourselves in that internal psychology, we run a risk that the emotion is too close to the trauma experienced and therefore, we open wounds without knowing how we will close them.

\section{Emotion as a driver in giving alternatives to imperialist logic}

Physical theatre gives us the opportunity so that we can create what we want. The concept we want covers all unimaginable possibilities. The freedom of not needing anything, just our bodies, to create what we want. What we want is quite different from what we need. Desire from creative freedom is the key point of the Theatre of Yes. This point is essential for participants to feel from an early age. Without that freedom, there is no depth to get into the most hidden emotions, to reach those remote entrails. If we want to reach the deepest emotions where the trauma is cystic, we need to beautify them. Traumas are made where emotions are holding the stories in. Often, these emotions are difficult to see, to talk about, to share with others or to understand. Theatre has the power to beautify them so that they can be reached 
without a painful experience. Using this art form, we can create new dimensions, exploring the character's journey, dreams or/and the reasons for their conflict. By embellishing them, we approach them to take action, accept them, reject them, discover them and assume them.

\section{Humility, generosity and honesty as an engine of change}

These three characteristics define a position of rebellion against cultural and social standards. It is a theatre based on group quality, where the qualities and characteristics of each one are at the service of the group and its stories.

- Generosity. It is an anti-ego theatre. My generosity helps the story progress. My creativity, my body, my stories, my emotions are at the service of the group. The whole is the result of the generosity of all participants. As participants enter the process, they open up physically, emotionally and verbally, accompanying the overtures of others.

- Honesty. The theatre we propose is not a theatre of pretending an emotion, of making people see. It is a theatre of showing deep emotions, often cycled. The proposed language has to show the insides of the stories. Without that level of honesty, the stories do not pass on to the public and, therefore, will not have the expected result. We need that honesty from the actors to reach that certainty, and therefore find the answers to the questions never answered. There is no dialogue with the public without that effective honesty. For me, dialogue in this context of theatre means the sharing of personal experiences without fabricating an ideal version of reality. Honesty harnesses the power of stories as a tool to break stereotypes. With this comes the acceptance of oneself, in soul, body and heart.

- Humility. The Theatre of Yes is not a space that generates acting skills. That is, quality does not come from the acting skills of the participants that take part in it. Humility starts from the acceptance of oneself. That is how I am, with all my travels, experiences that push me, sometimes they imprison me, and sometimes they corner me. I'm here. No more, no less. I'm here. Humility helps us to see each other, to get us out of masks. I do not pretend, here I am.

\section{Women and the deaf community}

The women's project is divided into two parts. In the first one, I showed the different techniques that the Theatre of Yes proposes. In the second part, we prepared a production about the stories themselves. I agreed to go to Mexico with a feeling of 
empowerment that I was living as a woman. For different reasons, I deeply reflected on what it was to be a woman and how easily the manipulation of patriarchy abducted us because we live the normalisation of so many behaviours. Women have few spaces to share, support and feel all the suffering. To visualise hope in a life shared with men. From the first day, I observed the need between them to touch each other: "Nobody had touched my face in this way since my daughter got older," they often said. Moreover, the need to experience moments of unity in a creative and emotional space: "I had never had a quality listening space." The first day, I proposed an exercise to make an image using everyone's body to create an object without which we could not live. One of the young women proposed we create the ancestors, those women who have transmitted so much to us. In the way she proposed it, pain and loneliness were visible. Furthermore, I asked them: "What do you want?" And they answered: "I want to feel free", "I want to feel safe", "I want the beings around me to be safe", "I want to be happy", "I want to get where I propose without obstacles".

During those days, we shared desires, guilt, intentions through the technique of physical theatre. I usually carry the workshops this way; I propose a technique, for example, rhythms. We practise the technique, we understand the rhythms bodily connecting emotionally with them, and we give them a voice. We support these rhythms with daily actions to understand how a physical exercise helps us to a more realistic action. We understand that changing rhythms changes our intention, helps us to clean. In pairs, they have ten minutes to propose a small story only using these rhythms. The next level is the creation using this technique for something more elaborate. In this case, I proposed the title The Release of Guilt. A topic that suggests without determining, one that it is deep but does not drag us into an imaginary prison.

The group is a supportive space in which we immerse ourselves in the search for simplicity as beauty. The group supports, but not by speech. It is supported from the creation, from the connection to each other from the body, from the movement of those beautiful bodies, which makes everybody comforted, stimulated, recognised, transformed by the poetics of beauty.

My function with them is joint creation; they create stories inspired by their own stories using the poetics of physical theatre. I help them to clean the movements, to amplify the emotion from the Greek choir, to understand the motivations of the characters, I ask about the different choices, I dissect where they want to go.

When someone proposed to me to work with deaf people, my first impression was respect and fear. The theatre group of the deaf, Guelaguetza of words and signs, is a group that has been working together for a while in the city of Oaxaca. I wondered, "How can I communicate? How can we work with subtle concepts such as beauty, with my lack of sign language?" On the first day, the group presented itself as a 
group of listeners and deaf people. In total, twenty people. I did not even know how to introduce myself; I felt lacking in resources to communicate. From the nerves of introducing myself, I decided to go directly to a game to connect with them. I started with the game of balls, passing ten balls to each other. It is a universal game and very effective. It helps with concentration and group connection. I felt that I was beginning to relax. I continued with my preferred body connection exercise that I do with all my groups. Absolute freedom. Bodies feel free to move, connect, shed tensions and express big, small, not to think. They look for a partner and dance together, change partners and express themselves.

I tried to explain the basics of physical theatre with my clumsy mimicry. The need to explain to you to go to the concrete in abstract concepts was complicated in my head. Action-emotion-sound. I realised that, when expressing emotion, they used their faces. Normal. They are used to surviving to use expressions on their faces to express themselves; it is their survival code. But there is a disconnection in the rest of the body. If it stays in the face and does not move towards the body, it will remain superficial in the "I pretend to be sad", not in the honesty that the work requires through the connection of the emotion with the support of the body. How to move from this superficial and survival code to a deeper code?

On the second day, I proposed a very simple exercise. I wrote different emotions on cards; sadness, disgust, anger, disappointment, happiness, freedom, laziness. In pairs, they had to express these using their hands. I showed an image on cardboard, and the listeners translated it to the deaf, and every two minutes, we changed our emotion. I stressed that they could not use the face to express themselves, only their hands. There I began to see the magic of the theatre; their bodies recovered, became alive, sensitive, authentic, the basis of the Theatre of Yes. The basis for entering deeper spaces. In the next phase, among four, they chose three emotions from the cards and interpreted them together.

In the last stage of the day, they could use their entire body, except the expressions of the face, to represent a creation. The title of it was The Journey of the Deaf. What do you not want, where do you want to go, what do you want, what do you wish, etc.? There were scenes full of frustration, anger, of feeling lost at times but accompanied by others, support, feeling lost because of not being able to hear. I began to see living bodies, honest stories and sensitive people behind the masks of survival. There, something deeper, more alive, more true appeared. For the next session, I suggested that we work with the obstacles and the next one how to overcome them. 
At the end of the project, the works were presented at the Theatre House (70 spectators) and the La Locomotora Forum (90 spectators). Participants were divided into two groups of women and the deaf youth group: The first group recounted the frustration of feeling violence just because they were female and how that led to suicide. The work told the reasons for not losing hope, being united, paddling together towards a more egalitarian space. Solidarity among women was one of the points reflected.

The piece told personal stories about family pressure not to follow your dreams ending in a job you hate without being able to stop the boss's sexual abuse. Also, of the daily persecution without the police doing any physical abuse against them. The work ended on their power and examples of help among women. From the concrete friendship, going on as solidarity between strangers upon arriving at a site for the first time, ending up helping those in danger by not listening to her own husband.

The work of the deaf community was their journey as young people, and the difficulties in suffering their disability had a brutal impact on the family, school level, among equals. That impact had affected their own personal consciousness. Solidarity between them, the respect for understanding and the effort to adapt to that tortuous culture for them was the final point.

After this experience in Mexico, I noticed not only that this methodology could be implemented in these two groups but also the need of these groups to express their own stories based on theatrical emotion. I noticed, from another perspective, their desire to show them in front of the public. The journey of emotions in their own body created an honesty they had never seen; the desire and the need to express personal stories created an extraordinary climate in front of female and male spectators. At the end of each work, we held a colloquium. It is essential to be able to share that cathartic moment. The men did not share any comments. Among our group, we commented on this fact, concluding that it was possibly one of the first times that male audience members were confronted with their own behaviour and needed time to understand how their behaviour resulted in the oppression of women. Only a blind man, who understood that discrimination shared the power of the work, lived through his own history. The women shared how they felt deeply connected with the stories shared.

Participants saw their stories heard, interpreted, expressed, lived, which gave meaning to their own experiences. They understood that what they experienced changed their lives, transforming them. They accepted these experiences as a springboard for new ones. History and people go together. Therefore, the acceptance that something happened to me helps me to accept myself. 
"Catharsis." Merriam-Webster's Encyclopedia of Literature, Merriam-Webster, Springfield MA, 1995, p. 217.

"Greek Chorus." Merriam-Webster, Merriam-Webster, www.merriam-webster.com/ dictionary/Greek chorus. Accessed on 10 January 2020.

Blutner, Adam and Daniel J. Wiener. Interactive and Improvisational Theatre: Applied Drama and Performance, iUniverse, 2007.

Gökhan, Özcan. "Psychodrama and Spirituality: A Practice-Friendly Review." Spiritual Psychology and Counseling, vol. 13, no. 1, pp. 39-55, spiritualpc.net/wp-content/ uploads/2019/03/03_Ozcan.pdf. Accessed 10 April 2021.

Lecoq, Jaques. El cuerpo poético: Una pedagogía de la creación teatral (Artes escénicas). Alba Editorial, 2003.

Moreno, Jacob Levy. Who Shall Survive? Nervous and mental disease Publishing Company, 1934.

Rionaldo, Julio. "Aesthetics of Catharsis" Prestige Journal, vol. 1, no. 3, 2019, pp. 1-7. 